23 Lucas CJ, Crown S, Stringer P, Supramaniam S. Further observation on study difficulty in university students including "syllabus-boundness." $\mathrm{Br} J$ Psychiatry 1976:199.598-603.

24 McManus IC, Richards P, Winder BC, Sproston KA. Final examination performance of students from ethnic minorities. Med Educ 1996;30:195200

25 Tomlinson RWS, Clack GB, Pettingale KW, Anderson J, Ryan KC. The relative role of 'A' level chemistry, physics and biology in the medical course. Med Educ 1977:11:103-8.

26 McManus IC, Tunnicliffe N, Fleming PR. The independent effects of intelligence and educational achievements in predicting final examination success. Med Educ 1990;24:181-4.

27 Atkinson P. The clinical experience: the construction and reconstruction of medical reality. Farnborough: Gower, 1981

28 Slotnick HB. How doctors learn: the role of clinical problems across the medical school-to-practice continuum. Acad Med 1996;71:28-34

29 General Medical Council. Tomorrow's doctors: recommendations on undergraduate medical education. London: GMC, 1993.
30 Marteau TM, Wynne G, Kaye W, Evans TR. Resuscitation: experience without feedback increases confidence but not skill. BMJ 1990;300:849-

31 Bulstrode C, Holsgrove G. Education for educating surgeons. BMJ 1996;312:326-7.

32 Schön DA. The reflective practitioner. New York: Basic Books, 1983.

33 Leiden LI, Crosby RD, Follmer H. Assessing learning-style inventories and how well they predict academic performance. Acad Med 1990;65:395-401.

34 Coles CR. Differences between conventional and problem-based curricula in their students' approaches to studying. Med Educ 1985;19:308-9.

35 Mårtenson DF. Students' approaches to studying in four medical schools. Med Educ 1986;20:532-4.

36 Tooth D, Tonge K, McManus IC. Anxiety and study methods in pre-clinical students: causal relation to examination performance. Med Educ 1989;23:416-21.

(Accepted 5 August 1997)

\title{
Home sampling versus conventional contact tracing for detecting Chlamydia trachomatis infection in male partners of infected women: randomised study
}

\author{
Berit Andersen, Lars Østergaard, Jens K Møller, Frede Olesen
}

See $p 351$

Research Unit and

Department of

General Practice,

University of

Aarhus, DK-8000

Aarhus C, Denmark

Berit Andersen,

research assistant

Frede Olesen,

consultant physician

Aarhus University

Hospital, DK- 8000

Aarhus C

Lars Østergaard,

senior registrar of

infectious diseases

Jens K Møller,

director of clinical

microbiology

Correspondence to:

Dr Andersen

ba@alm.aau.dk

BMJ 1998;316:350-1
Urogenital infections with Chlamydia trachomatis are widespread and usually asymptomatic. Major complications from infection include ectopic pregnancies and female infertility. ${ }^{1}$ Although contact tracing reduces the prevalence of chlamydia infection, ${ }^{2}$ the test rate among partners is often low, partly because male contacts have to have a urethral swab taken by a doctor.

As the polymerase chain reaction can successfully detect infection in urine samples, ${ }^{3}$ we investigated whether the test rate could be increased by asking the male contacts of infected women to send a urine sample directly from home to a laboratory instead of having a doctor take a urethral swab.

\section{Subjects, methods, and results}

Ninety six women with $C$ trachomatis infection seen in general practices in Aarhus County, Denmark, were randomly divided according to their date of birth into an intervention group (45 patients) and a control group (51 patients). Women in the intervention group were asked to complete a questionnaire, including the number of male sexual partners over the preceding six months, and to supply their partners with an envelope containing a $10 \mathrm{ml}$ sterile container, information on collecting the first urine sample of the morning, and a prepaid envelope for returning the sample to the laboratory at the Aarhus University Hospital. Envelopes supplied by the control group contained a request for the partner to visit his doctor as well as a contact slip and a prepaid envelope to be given to the doctor for returning a urethral swab sample.

Swab samples were examined by enzyme immunoassay (MicroTrak II, Behring, Germany). Specimens with an optical density greater than $30 \%$ of the recommended cut off point were confirmed by polymerase chain reaction assay (Amplicor, Roche, Switzerland). ${ }^{4}$ Urine samples were analysed by the same polymerase chain reaction. A sample was considered positive only if the result was confirmed on retesting.
The table shows the results of contact tracing. Forty four out of $65(68 \%)$ partners were examined in the intervention group compared with 19 out of 68 (28\%) in the control group $\left(\chi^{2}=19.50 ; \mathrm{P}<0.01\right)$. The difference in test rate was 0.4 (0.68 minus 0.28$)(95 \%$ confidence interval 0.24 to 0.56). Although not significant, there were more new cases of $C$ trachomatis per index case in the intervention group $(0.27)$ than in the control group (0.14). The difference between the two groups was 0.13 ( -0.03 to 0.29 ). Furthermore, there was a trend for partners of women in the intervention group to be tested earlier than those of women in the control group, with a mean delay time of 12.6 days and 17.7 days respectively. Thus the difference between the two groups was 5.1 days $(-1.6$ to 11.8). The prevalence of $C$ trachomatis in samples from the intervention and control groups was $27 \%$ and $39 \%$ respectively.

Tracing of male contacts of women with Chlamydia trachomatis infection

\begin{tabular}{lcc} 
& $\begin{array}{c}\text { Intervention } \\
\text { group }(\mathbf{n}=\mathbf{4 5})\end{array}$ & $\begin{array}{c}\text { Control group } \\
(\mathbf{n}=\mathbf{5 1})\end{array}$ \\
\hline Partners contacted & & \\
\hline No & 65 & 68 \\
\hline Median No per index case & 1 & 1 \\
\hline Mean No per index case & 1.44 & 1.33 \\
\hline Range & $0-4$ & $0-4$
\end{tabular}

Partners tested

\begin{tabular}{lcc}
\hline No $(\%$ of those contacted) & $44(68)$ & $19(28)^{\star}$ \\
\hline Mean No per index case & 0.98 & 0.37 \\
\hline Range & $0-3$ & $0-1$
\end{tabular}

\begin{tabular}{lcc}
\hline Partners infected & $0-3$ & $0-1$ \\
\hline No (\% of those tested) & $12(27)$ & $7(39)$ \\
\hline Mean No per index case & 0.27 & 0.14
\end{tabular}

Mean No per index case

Mean delay (days) 12.6 17.7

*Result unknown for one partner. 


\section{Comment}

Contact partners of women with $C$ trachomatis infection may be deterred from seeking medical help because of the intimate nature of the infection and because a urethral swab is needed. Urine samples obtained at home provide a non-invasive and less time consuming alternative.

A similar procedure for contact tracing of female partners of men infected with $C$ trachomatis should be considered as the organism has been detected in urine samples from women. ${ }^{5}$

We thank the participating general practitioners.

Contributors: BA coordinated the primary study hypothesis and the core ideas, designed the protocol, obtained approval from the ethics committee, coordinated inclusion of patients, scanned the data, and coordinated the interpretation of results and writing of the paper. $L \varnothing$ discussed the primary hypothesis, core ideas, analysis, and protocol design and participated in the interpretation of results and writing of the paper. JKM discussed the hypothesis and ideas, led the analysis of the samples obtained, participated in the interpretation of results, and edited the paper. FO discussed the hypothesis and core ideas and participated in the protocol design, coordination of contact with the general practitioners, the interpretation of results, and the writing of the paper. FO is the guarantor of the paper.

DAK

Funding: University of Aarhus, Denmark and Nycomed

Conflict of interest: None.

Cates W Jr, Wasserheit JN. Genital chlamydial infections: epidemiology and reproductive sequelae. Am J Obstet Gynecol 1991;164:1771-81.

2 Ripa T. Epidemiologic control of genital Chlamydia trachomatis infections. Scand J Infect Dis Suppl 1990;69:157-67.

3 Jaschek G, Gaydos CA, Welsh LE, Quinn TC. Direct detection of Chlamydia trachomatis in urine specimens from symptomatic and asymptomatic en by unich men by using a $1993 ; 31: 1209-1$

4 Østergaard L, Møller JK. Use of PCR and direct immuno-fluorescence microscopy for confirmation of results obtained by Syva MicroTrak Chlamydia enzyme immunoassay. J Clin Microbiol 1995;33:2620-3.

5 Østergaard L, Møller JK, Andersen B, Olesen F. Diagnosis of urogenital Chlamydia trachomatis infection in women based on mailed samples Chlamy trachomatis infection in women based on mailed

(Accepted 25 April 1997)

\title{
Opportunistic screening for chlamydial infection at time of cervical smear testing in general practice: prevalence study
}

\author{
Pippa Oakeshott, Sally Kerry, Sima Hay, Phillip Hay
}

Genital infection with Chlamydia trachomatis is the most common, curable sexually transmitted disease in England and Wales. ${ }^{1}$ In the United States and Sweden screening programmes have been shown to be effective in reducing the prevalence both of cervical infection with $C$ trachomatis and of sequelae such as pelvic inflammatory disease. ${ }^{12}$ In Britain a national selective screening programme has recently been recommended, ${ }^{3}$ but more data on the prevalence of chlamydial infection in different healthcare settings are needed. ${ }^{3}$ There have been no large studies of more than 1000 patients done on the patient populations from inner city general practices in the United Kingdom. ${ }^{1}$ The aim of this study was to determine the prevalence and predictors of chlamydial infection in women aged $<35$ having cervical smear tests in inner London general practices.

\section{Subjects, methods, and results}

Thirty seven practice nurses and 108 general practitioners from 30 practices participated in the study. The total patient population served by the practices was 192 000. The mean Jarman underprivileged area score was 23 (range 15-33). (A positive score indicates social deprivation and compares with a mean score for England and Wales of 0.) Twelve practices had only one or two practitioners.

Each practice was asked to recruit consecutive women aged $<35$ who were attending for a cervical smear test, record their clinical details, test them for chlamydia, and ask them to complete a confidential questionnaire on sexual health. Informed consent and ethical approval were obtained. Women who had taken antibiotics in the previous month were excluded.

Practice nurses and general practitioners were taught to take endocervical specimens for detection of chlamydial infection. These were analysed at St George's Hospital by enzyme immunoassay (Microtrak Syva II, Behring Diagnostics, Milton Keynes) and confirmed by direct fluorescent antibody testing. Six possible predictors of infection found in other studies were also examined: age $<25$, ethnic group, number of sexual partners, condom use, the presence of mucopurulent vaginal discharge, and the presence of a friable cervix with bleeding on contact.

Between May 1994 and October 1995, 1382 women aged 16-34 (mean age 27 ) were recruited. The mean number of subjects recruited from each practice was 46 (range 11-102). Practices were asked to complete recruitment rate forms for a sample of 25 consecutive women aged $<35$ attending for a cervical smear test. Practices recorded the age and ethnic origin of patients who were not asked to participate or who refused. Two practices had recruited 50 participants before the forms were introduced. Analysis of 18 forms returned by the practices showed that the age and ethnic origin of the $55 / 415$ (13\%) women who were not asked to participate and the $31 / 415(7 \%)$ who refused were similar to those patients who agreed to participate. Altogether, 1049 women $(76 \%)$ returned postal questionnaires. Of these women, 838/1040 $(80 \%)$ were white, $84 / 1040(8 \%)$ of Afro-Caribbean origin, 48/1040 (5\%) of black African origin, 29/1040 (3\%) of Indian subcontinent origin, and 41/1040 (4\%)
See p 350

Department of General Practice and Primary Care, St George's Hospital Medical School, London SW17 0RE Pippa Oakeshott, clinical lecturer Sally Kerry, statistician

Sima Hay, research assistant

Department of Genitourinary

Medicine, St George's Hospital Medical School

Phillip Hay, senior lecturer

Correspondence to: Dr Oakeshott oakeshot@sghms. ac.uk

BMJ 1998;316:351-2 